\title{
OBSERVATIONS ON SYPHILIS OF THE NERVOUS SYSTEM
}

\section{BEING AN EPITOME OF THE PRESIDENTIAL ADDRESS DELIVERED BEFORE THE MEDI- CAL SOCIETY FOR THE STUDY OF VENE- REAL DISEASES, JANUARY 29, I932*}

By DAVID LEES, D.S.O., F.R.C.S.Ed., D.P.H.

LAdies AND Gentlemen,--In the first place I wish to thank the members of this Society for having re-elected me as President, and to say how keenly I appreciate this honour. To-night, in delivering this Presidential address, I hope you will excuse me if I do not keep to the written word. It is very difficult to condense so large and wide a subject before an expert and critical audience. I hope, when the address is published in full, to have the benefit of your comment and criticism.

In reviewing the literature, I find references to neurosyphilis as far back as I635, when Sennert spoke of this condition. A hundred years later, Astruc, in a masterly treatise, which I advise everyone to read, made reference to syphilis of the nervous system. In I798 we have the first clinical description of general paralysis, by Haslam, and later by Esquirol and Bayle. In I875 Fournier started a great controversy on the ætiology of tabes and general paralysis of the insane, and for many years we had men like Lancereux and Charcot, Cowers and Hunter opposing the view that these diseases were due to syphilis. On the other hand, Fournier, Bramwell, Hutchinson and others became more and more convinced of the close relationship between syphilis and tabes and G.P.I.

The next landmark in our knowledge of nerve syphilis was the institution of lumbar puncture by Corning in I885; the application of this method to diagnosis did not come until the work of Ravaut and his colleagues in I903. The discovery of the Wassermann test in I907, and the demonstration of the spirochæte in I9I3 by Noguchi and Moore, in the spinal cord in general paralytics

\footnotetext{
* The full address will be published at a later date.
} 


\section{BRITISH JOURNAL OF VENEREAL DISEASES}

and in a tabetic closed the last links in the chain of evidence that these conditions were due to syphilis.

We may say that syphilis is the most important cause of, and probably, in middle life, the most serious organic disease of the nervous system. Cerebro-spinal syphilis occurs, to the exclusion of tabes and paresis, in about 4 per cent. of all people who acquire syphilis. In the cases of syphilis coming under my care during the last twelve years in Edinburgh, namely, I3,I9I, there have been 603 cases of neuro-syphilis, i.e., 4.5 per cent. The incidence was greater in males than in females. The incidence of G.P.I. and especially of tabes increased the numbers. Fordyce stated that 25 per cent. of all cases of syphilis are candidates for neuro-syphilis ; Keyes gave the figure as $2 \mathrm{I}$ per cent. At no time in the life of the syphilitic patient is he free from the possibility of nerve syphilis. There is no sharp line of demarcation between generalised syphilis and syphilis of the nervous system. Ravaut found that 70 per cent. of roo patients had abnormal cerebro-spinal fluids, and his work has been confirmed by many others, some of whom say that probably every case of syphilis which reaches the secondary stage has more or less involvement of the central nervous system. It is open to question whether many of these cases, which in the early stages of syphilis have a fluid which is pathological, do develop severe neuro-syphilis later on; this, however, does not lessen the importance of recognising such cases at the earliest possible stage, so that appropriate treatment may be instituted.

Is there any type of case which is prone to develop nerve syphilis? Levaditi and Marie in their work on neurotropic strains of Spirochata pallida did not take sufficient account of a special susceptibility of the nervous tissues of the host. This view is preferred by most syphilologists in this country, and possibly trauma is also a potent factor in causing any case of systematic syphilis to develop neuro-syphilis. Many of the arguments in favour of different strains of organism, neurotropic and dermotropic, are not sound and do not conform to our clinical experience. The involvement of the nervous system is more dependent on the susceptibility of the nervous tissue. It has been argued also that extragenital syphilis is more likely to be followed by neuro- 


\section{SYPHILIS OF THE NERVOUS SYSTEM}

syphilis than is genital syphilis, but the work of Mills effectually disposed of this idea, as 28.35 per cent. of his cases of genital chancres developed neuro-syphilis as opposed to II 4 per cent. of extra-genital cases.

Since the advent of salvarsan the question has been raised whether the amount of neuro-syphilis has increased, and whether salvarsan is a cause of neuro-recurrences. It is interesting to note that an authority like Gennerich, who has made a life study of this subject, and Benario absolved the drug entirely. Colonel Harrison has, with the help of his previous assistants and colleagues, investigated cases treated with " 606" and "9I4" in the army, and found nothing to support this argument. In this series of I3,I9I cases I have found only two cases of neuro-recurrence. The case could not be put better than was done by Browning and Mackenzie. "It is obvious that the phenomena known as nerve relapses or neurorecurrences are not peculiar to patients who have been treated with salvarsan. The affections are the expression of a syphilitic lesion and are cured by specific treatment, most readily by salvarsan itself." I am in agreement with their view, and it is the consensus of opinion of practically all syphilologists; there are still a few neurologists who find difficulty in accepting this view.

I do not propose to go into the pathology of syphilis of the nervous system, as it is such a large subject. I will touch on it only to show how the disease causes such a variability of symptoms. Those who study the effect of it on the nervous system must recognise that the clinical symptoms must be manifold, and that certain groups of symptoms occur with special frequency. Disease of meninges, blood vessels, and parenchymatous tissue, either primary, or due to interference with or lack of nutrition, will cause varying symptoms. Often more than one tissue is involved, and a gumma and hyperplastic infiltration may occur in combination, and there may be changes in the nervous tissue itself.

Syphilis of the nervous structures shows wide variations in its nature, its intensity, and its course, the extremes being simple involvement of meninges and vessels, and, on the other hand, inflammation or destruction of the central cells and fibres of the nervous system.

It is important for us to recognise the prodromal symptoms and signs. None are definitely diagnostic of 


\section{BRITISH JOURNAL OF VENEREAL DISEASES}

cerebral syphilis, but all are danger signals in the case of a patient who has systemic syphilis ; they are headache, insomnia, psychic changes, and the wide group which may be included in neurasthenia. All may be the result of toxæmia, but it is just as possible they are due to a definite invasion of the nervous system by the spirochæte. Symptoms and signs, such as loss of light reflexes, absent knee-jerks, etc., are more striking, but this is not the time to refer to them, as they are well known to us all.

In spinal syphilis there is often tenderness over the spine, radiating pains in the back, numbness and tingling and other sensory disturbances, with loss of sensation in the lower limbs. Bladder conditions may exist, with loss of control; sciatica is not uncommon. Both cerebral and spinal syphilis may be protean in their manifestations; they often occur together, and both simulate many other diseases. The symptoms are transient, and may be absent over long periods. While clinical diagnosis is of great value and should always be practised in every case of suspected neuro-syphilis, it should be supplemented by an examination of the cerebro-spinal fluid.

That raises the question as to when one should examine the cerebro-spinal fluid in any case of syphilis. It was discussed at the Edinburgh meeting of the British Medical Association, where the general opinion was that it should be examined immediately, if the case shows the slightest clinical sign of abnormality of the nervous system when first seen; in cases of systemic syphilis which have been treated intensively, but have not reacted serologically; it is advisable to examine the spinal fluid after six months intensive treatment ; further, all cases of syphilis should have the cerebro-spinal fluid examined three months after cessation of all treatment between the third and fourth year before considering them as likely to be cured. I am inclined to go further and examine the cerebro-spinal fluid of all cases of syphilis at the end of the first year, if possible, and repeat it later on before discharge. I do not rely on one examination of the fluid. The repetition of the examination enhances the value of negative findings. It is well to remember also that there are cases of nerve syphilis which do not show evidence of it on examination of the cerebro-spinal fluid. 


\section{SYPHILIS OF THE NERVOUS SYSTEM}

How should this fluid be obtained ? There are three methods-ventricular, cisternal, and lumbar puncture. Cisternal has in its favour a lessened incidence of lumbar puncture headache. On the other hand, one doubts whether junior assistants might be allowed to practise it freely, as we allow them to do lumbar puncture. The reason why there is no headache after cisternal puncture is that immediately after the operation the patient is put into the sitting posture and the fluid may not rise as high as the puncture level. Puncture headache after lumbar puncture is very troublesome, and no doubt prevents many physicians from practising this method freely. The headache is said to be due to one or more causes, chiefly leakage from the puncture wound, or it may be due to some alteration in the pressure. The former was disproved by Becht and Matill, who showed that it was dependent more on capillary blood pressure, and that there was a spasm of the cerebral capillaries, as occurs in megrim. We started using "impletol" to control this spasm, and after twelve months' experience we are satisfied that the incidence of lumbar puncture headache has decreased, and it is now found in a little less than 2 per cent. of the cases.

What are the alterations in the fluid to which syphilis gives rise? There are four cardinal tests : cell count, globulin estimation, the Wassermann test, and one of the sol tests. The first two are an indication of the meningeal involvement. We cannot assume that those cases which, in the florid stage of syphilis, show alterations in the fluid which are suggestive of a pathological condition will necessarily go on becoming more pathological. But in late cases the changes are often quite definite, and, if there is a strong positive Wassermann reaction of the cerebrospinal fluid, there is no condition other than syphilis of the nervous system which causes this. There are cases of syphilis of the nervous system which do not always give a strong positive Wassermann of the fluid, a cerebral gumma for instance; this is because the syphilitic lesion is partly cut off from the fluid which is bathing the meninges. In syphilitic hemiplegia a negative Wassermann of the cerebro-spinal fluid is not infrequent. In tabes the changes in the fluid are variable.

In assessing the diagnostic importance of the various tests, it is important to read them in association with 


\section{BRITISH JOURNAL OF VENEREAL DISEASES}

the clinical picture. Many other disorders of the nervous system may produce an increase of cells, an excess of protein, or an altered gold sol curve. There is no pathological condition other than syphilis which will give a strong positive Wassermann test in the cerebro-spinal fluid.

Another important question is the weight we must attach to a paretic curve in the colloidal gold test. It may occur in cases which are not paretic in the clinical sense. If it does, and if treatment does not alter the paretic nature of the curve, the prognosis is bad, and it indicates almost certainly an early case of G.P.I.

The results of the Lange test must always be interpreted with caution and only in association with other findings in the fluid.

Apart from the positive Wassermann, any abnormal state of the cerebro-spinal fluid should only suggest that it may be a case of cerebral syphilis.

With regard to the findings in cases of juvenile neurosyphilis, it has been said that in all cases of congenital syphilis the fluid shows an increased cell count. This is not our experience in the ninety-seven cases examined in this series. In juvenile tabes and juvenile paresis there is no doubt that the picture is exactly similar to that in acquired syphilis.

In passing, I should like to comment on the incidence of neuro-syphilis in congenital cases. We should, in my opinion, pay more attention to this, because on examining the literature in this country, I find little reference to it, and there is no doubt there are many asymptomatic cases. Jeans found neuro-syphilis in one-third of his cases and Kingery in 28 per cent. The incidence in this series is 16 per cent.

An accurate clinical classification of the 603 cases under review is very difficult. This is due to the variability of the symptoms and signs and to the simultaneous involvement of the meninges, vessels, and parenchyma in many cases. In others both brain and cord are involved. Of the male group of cases, 382 in all, 53.4 per cent. are tabes dorsalis and $2 \mathrm{I}$ per cent. G.P.I. Taboparesis accounts for 8.I per cent., vascular and meningovascular cases number Io per cent., ocular palsies 2.6 per cent., latent neuro-syphilis $3 \cdot I$ per cent., gumma $I \cdot 3$ per cent., and 8 th nerve deafness 0.5 per cent. The incidence 


\section{SYPHILIS OF THE NERVOUS SYSTEM}

in females and in children is less. In the total 603 cases there were ninety-seven cases of congenital neurosyphilis, i.e., I6 per cent. in 13,000 cases.

A very interesting group, especially from the point of view of treatment, were the cases of tabes with optic atrophy, which totalled forty-six.

Differential diagnosis from other organic diseases of the nervous system often presents difficulties, and it has to be remembered that conditions such as epidemic encephalitis or multiple sclerosis may precede or follow neuro-syphilis and complicate the symptomatology. So, too, with other conditions.

In considering the prognosis, interstitial neuro-syphilis reacts well to treatment, and the prognosis is good if treatment is started early, before damage has been done to the nerve structures. The growth of gummatous lesions can be arrested, and when the nerve structures have only been compressed, recovery may be complete.

The prognosis in parenchymatous syphilis varies with the time at which treatment is commenced. If damage to the brain and cord structures has been done, the killing off of spirochætes will not regenerate the neurones. But in many cases we can arrest the destructive process by efficient treatment, at any rate for a time. Since the introduction of malarial and tryparsamide treatment, in many of the cases of G.P.I. resulting from a chronic inflammatory lesion and lymph stasis, a better outlook can be given than years ago. A few years ago an eminent physician stated that syphilitic patients must continue intermittent treatment for the rest of their lives, and another has said he had never seen a definite cure in any case of neuro-syphilis. Some of the cases which have been treated by more recent methods have had very long remissions, and I am inclined to think that the time is now ripe for alienists or neurologists to define a remission and to state how they determine between a remission and a potential cure. Some of the cases which have had these long remissions of six to seven years may be free from any subsequent syphilitic invasion of the nerve tissue.

The treatment of neuro-syphilis presents difficulties which are much greater than those confronting us in systemic syphilis. In many of the cases important structures, such as the heart, are damaged, and this 


\section{BRITISH JOURNAL OF VENEREAL DISEASES}

contra-indicates the intensive treatment which might otherwise be adopted. As the pathological process is not always the same, each case must be studied separately. We must in every case tone up the patients' tissues and so increase the natural resistance. Many antisyphilitic drugs have been tried in addition to mercury and iodides in treating neuro-syphilis, and excellent results have been obtained, especially in cases of vascular and gummatous lesions. In every case which allows of it a preliminary course of iodides is desirable, or it may accompany the other forms of treatment. A hypertonic solution of sodium iodide, administered intravenously, is valuable, and we have formed the opinion that it enhances the value of tryparsamide and other drugs in cases of root pains and crises.

Treatment by the arsenobenzols, as applied to systemic syphilis, is quite applicable to neurosyphilis. When accompanied by mercury or bismuth it is more effective still. The largest field for it is in meningo-vascular syphilis, in gummata, and in early tabes, and it is better given frequently in small doses than in large doses at longer intervals. Intensive treatment followed by spinal drainage has also been tried and has given promising results in similar cases.

During the last two decades intraspinal treatment obtained a great vogue in America. This method was suggested originally by Browning and Mackenzie, of Glasgow, and shortly afterwards was practised by Marinesco of Bucharest, and Robertson of Edinburgh. Swift, Ellis, Fordyce and many others in America, have claimed favourable results. Others, e.g., Sachs, Kaliski and Strauss have definitely condemned this method. We have satisfied ourselves that the patients treated either by spinal drainage or by any form of intraspinal treatment do not respond any more quickly than do those treated by intensive intravenous and intramuscular therapy. The same comment may be applied to intracisternal treatment.

Sir Frederick Mott summed up the position very truthfully: "It is certain that cerebrospinal syphilis occurring within the first few years after infection has yielded to treatment by mercury or arsenobenzol compounds, and provided the treatment has been adopted before thrombosis of vessels and degenerative softening 


\section{SYPHILIS OF THE NERVOUS SYSTEM}

of the neuronic structures had occurred, surprisingly satisfactory results were obtained, whereas, in general paralysis, although arrests and even cures were announced as a result of intensive treatment by arsenobenzol compounds or their substitutes either by intravenous injections of the drug or by intrathecal injections of salvarsanised serum, further experience only showed that a successful remedial treatment had yet to be found."

A new preparation, named tryparsamide, was introduced first in a clinical study on trypanosomiasis by Pearce in I92I. The results obtained in the treatment of neurosyphilis, published in I922 by Lorenz and his colleagues, were very striking. Further clinical reports were published by these and other workers, and there appeared to be a consensus of opinion that it was proving itself a very valuable drug in the treatment of many cases of neuro-syphilis. There is no doubt also that better results were obtained when used in conjunction with bismuth or mercury. We commenced to use this drug in I924, and have administered it in a series of 500 . cases of nerve syphilis. The results in many cases are very convincing, and there is no doubt that the more you use the drug the more you like it. Just as we do not expect that a case of florid systemic syphilis is cured, although after a course of 4 to 5 grammes of " 9 I 4 " it gives a negative W.R. reaction, so we need not expect a case of nerve syphilis to remain negative serologically, to have no clinical recurrence, and to remain permanently. well after one course of tryparsamide. The administration of the drug must be continued, if necessary, for years until a permanent clinical and serological quiescence is obtained and stabilised. Because of its tonic effect on the patient and the feeling of well-being it creates and the increase of weight, course after course of tryparsamide can be given with great benefit to the patient and very little risk. In very few cases is hospitalisation necessary. In children tryparsamide can be given intramuscularly either dissolved in sterile distilled water or in a solution of guiacol, glucose, and distilled water, when it seldom causes pain. In our series we had one case of abscess of the buttock, due primarily to an error in the sterilisation of an ampoule.

What are the contra-indications to its use ? When first introduced by Pearce and Brown it was stated that it 


\section{BRITISH JOURNAL OF VENEREAL DISEASES}

might cause serious damage to the eye by producing amblyopia. This was done to ensure that the drug would not fall into disrepute if such an accident happened, and, to make certain that those using it should examine the discs and the fields of vision, or get an ophthalmologist to do so before commencing treatment. In 500 cases in which it was used by us, there has occurred only I per cent. of permanent damage to the eye in the form of amblyopia. We feel certain therefore that the risk of eye trouble has been over-stated. If amblyopia is going to develop as a result of the use of tryparsamide, it does so during the first four or five injections. Cases which have a definite primary optic atrophy can in our experience be given tryparsamide in smaller doses, with definite benefit, and in many cases complete arrest of the symptoms and signs of the disease. In such cases it must be given guardedly, and the optic discs and fields of vision must be watched at regular intervals.

I propose to give you later the details of two cases in which ophthalmologists noted a striking arrest of the progress of the optic atrophy. One of my ophthalmic colleagues holds the view that, if the optic atrophy is due to nerve syphilis, and if tryparsamide is the drug of choice in neurosyphilis, tryparsamide is the drug to use in optic atrophy. In this series of cases of neuro-syphilis, in five cases only have we had to stop giving the drug because of definite objective symptoms of amblyopia. Subjective symptoms arise from time to time, but they are due in most cases to giving too large a dose. It must be remembered that the same dose cannot be given to all adults, irrespective of their weight and the maximum in any single dose should be 3 grammes. The average number of cases having subjective transient symptoms is from 3 to ro per cent., while permanent damage may occur in $I$ to 3 per cent.

In certain cases an injection of tryparsamide may at first accentuate the symptoms of disease, especially at its first administration. This occurs mainly in cases of G.P.I., who may become more excitable, or in tabetics, whose pains are exacerbated. These reactions are in the nature of a Herxheimer reaction, and are not a contraindication to its use. In other cases a transient albuminuria or a localised dermatitis may arise, but these complications are rarely if ever severe. 


\section{SYPHILIS OF THE NERVOUS SYSTEM}

From observation of its action in cases of neurosyphilis over a period of eight years, we are satisfied that it can be administered in the doses and manner we have suggested, namely, 3 grammes per week over long periods, at little inconvenience to the patient and at a comparatively small cost. The more we have used this preparation, and the longer we have observed its action, the more favourable is the impression which we have formed of its value in many cases of neurosyphilis.

When given in conjunction with bismuth metal or a salt of bismuth the results in cases of meningo-vascular syphilis have been consistently good, apart from meningomyelitis. In vascular syphilis also the results are good. In early cases of G.P.I. it exerts a very favourable influence, and similarly in early cases of tabes dorsalis. In all gummatous lesions the results are good. In cerebro-spinal syphilis of the more advanced type it takes a longer time to show its influence, but does so if the treatment is persevered with. In the established cases of tabes there is often quite a marked improvement, especially if given in association with intravenous injections of sodium iodide. In advanced tabetics it is important to re-educate the patient by Fraenkel's exercises with a view to lessening the ataxia. In some of the established cases of G.P.I. its effect is quite striking; in the more advanced cases, however, we have not had the same good results unless the patient has previously been submitted to some form of pyrexial treatment. Clinical improvement appears to precede improvement in the pathological findings of the spinal fluid. This is in conformity with the observations which have been made by many others.

This observation is, in the main, true in cases of general paralysis which may require course after course of treatment over a period of years to effect a favourable influence on the Wassermann test of the cerebro-spinal fluid. Bunter is of opinion that while complete negativity is capable of achievement, it is usually at the cost of roo to 150 injections.

In this series of cases the cell count has been reduced to normal ( $\mathrm{I}-5$ cells per cubic centimetre) in every case except two after one course of treatment (24 gm.).

The globulin content has been reduced to a trace in the same period in the greater number of our cases. 


\section{BRITISH JOURNAL OF VENEREAL DISEASES}

The Lange reaction has been altered from a paretic curve to a luetic one after one course in some cases of G.P.I., and in practically all except the most advanced and intractable cases of G.P.I. after three or four courses (72 to $90 \mathrm{gm}$.). In other types of neuro-syphilis the luetic curve is diminished in intensity and becomes negative in most cases after two or three courses of treatment.

In meningo-vascular syphilis, in gummata, in tabes dorsalis, and in cerebro-spinal syphilis, the Wassermann test of the cerebro-spinal fluid is influenced favourably in the great majority of the cases. This is in agreement with the more recent observations of Stokes and Lorenz. Moore and his co-workers did not obtain so favourable results, and we agree with Stokes that this is almost certainly due to Moore using tryparsamide alone, and not in conjunction with bismuth or mercury. There is no doubt that the combination gives better results in influencing the cerebro-spinal fluid findings, and still more so in rendering negative the Wassermann test of the blood, which should be aimed at simultaneously with the former.

When we weigh up the simplicity of the technique of its administration, the ability to give it to ambulant cases, and the consequent lack of inconvenience to the patient, the absence of any serious manifestations of intolerance if proper precautions are taken, its tonic and stimulating effects, and at the same time see the beneficial clinical and serological results which eventuate in a good percentage of cases, there is no doubt that in this drug we have a very valuable asset in the treatment of neuro-syphilis.

We are not in a position to claim, and are far from claiming, that this drug should be administered in every. case of neuro-syphilis.

Every case must be regarded as an individual problem before deciding on the line of treatment.

In general paralysis, although the transformation which it effects in some of the earlier cases is striking and spectacular, it is open to question whether in established and more particularly in advanced cases, pyrexial treatment does not lead to a more rapid amelioration of the clinical picture.

There is no doubt that pyrexial treatment also has 248 


\section{SYPHILIS OF THE NERVOUS SYSTEM}

a definite place in the treatment of neuro-syphilis, and particularly in cases of G.P.I. Malaria treatment, introduced by. Von Jauregg in I9I7 and reported on by him in I922, was administered in about seventy of our cases. The cases were selected on the following grounds: (I) those showing pronounced mental symptoms in which the disease appeared to be advancing rapidly; (2) cases of G.P.I. which had previously received prolonged treatment with anti-syphilitic drugs, such as tryparsamide and bismuth, but had not shown a favourable response: (3) cases which were already well advanced when first seen in the medical wards of the hospital or in the V.D. Clinic.

It is our experience that the mental symptoms are much more favourably influenced by malaria than the serological signs, especially in cases of G.P.I. Successful results were obtained in 30.6 per cent. of the adult cases of G.P.I. based on the standard that there were no mental symptoms present and that the patient had sufficiently recovered to be able to resume his usual occupation. In cases of congenital neuro-syphilis the percentage of success was $2 \mathrm{I} \cdot 4$ per cent. This is at variance with the findings of Jonson and Jefferson, who considered that juvenile general paralysis of the insane is a contraindication to malarial therapy.

Other forms of pyrotherapy have been employed by us, notably sulphosin, as suggested by Schroeder.

We doubt, however, if they are as valuable as malaria, and their only advantage is their comparative safety, especially in cases of myocardial degeneration. In every. case treated by malaria or other pyrexial methods we are convinced that it is important to follow up this treatment by courses of tryparsamide and bismuth with a view to stabilising the results of the pyrexial treatment and to eradicating the pathological content of the cerebro-spinal fluid.

At this stage eight selected cases were reported, in six of which the results of tryparsamide were spectacular, and in which complete remission of symptoms had been present over prolonged periods of observation. In the remaining two cases malaria treatment had been given, and was followed by tryparsamide with equally successful results. The cases were as follows :-

(I) Gumma of the frontal lobe with papillodema of the v.D. 


\section{BRITISH JOURNAL OF VENEREAL DISEASES}

optic discs, jacksonian fits, and tremors of left side of body.

(2) Case of vascular syphilis with transient paresis of right arm and leg, aphasia and agraphia followed by hemiparesis.

(3) Case of cerebro-spinal syphilis with temporary loss of consciousness for forty-eight hours, followed by confusion and excitement. Case proved resistant to intensive " 9I4" and $\mathrm{Hg}$ treatment.

(4) Case of tabes with marked ataxia and a pronounced syphilitic psycho-neurosis.

(5) Case of optic atrophy with cardiovascular syphilis ; tabetic ataxia complicated by spontaneous fracture of navicular bone.

(6) Case of optic atrophy and tabes, with loss of control of the sphincters.

(7) Case of advanced G.P.I., with bed sores, auricular fibrillation, septic cystitis, etc.

(8) Case of G.P.I., which became maniacal after malaria treatment.

\section{General Remarks}

In spite of the enormous amount of work and the numerous observations which have been made in neurosyphilis, it still abounds in unsolved problems. No other disease of the nervous system is so prevalent as syphilis, and as Mott stated, "At no period is a syphilitic patient safe against brain syphilis." In our experience a mild anti-symptomatic treatment is almost as bad as no treatment as regards the incidence of late specific infections. Intensive and prolonged treatment is of value in preventing the incidence of late syphilis and of neuro-syphilis, especially if arsenic and bismuth or arsenic and mercury are given in combination. Some Norwegian studies in syphilis have raised a doubt on this question, and it was discussed fully at the Scandinavian Neurological Congress in I926. In the cases of Professor Boëck, which were followed up by Bruusgaard and Dahlström, it was stated that only 0.6 per cent. developed G.P.I. and that half that number suffered from tabes, and that the incidence of any form of neuro-syphilis in Boeck's cases was remarkably low, although they had received neither mercury nor "606." Even if this is proved, and there is 


\section{SYPHILIS OF THE NERVOUS SYSTEM}

reason to doubt it, we doubt if this method and this attitude of masterly inactivity is justifiable. It certainly would entail an increased and very grave risk of the spread of syphilis to the rest of the community.

In I922 another Continental authority, Kyrle, recommended as a method of preventing neuro-syphilis the combination of malaria and salvarsan treatment in all cases of syphilis which had reached the florid stage or were of one to two years' duration. We doubt if this method is justifiable, and are in agreement with Zieler that it is not a method which is suitable for general application. It is certainly not an economic proposition in this country on account of the scarcity of hospital beds for these cases.

\section{CoNCLUSIONS}

(I) The best methods of preventing neuro-syphilis are the education of the people in avoiding the risk of syphilis, the institution of treatment of every case in the seronegative stage, and its prolonged treatment and observation for at least two years. In this treatment a combination of arsenobenzol and bismuth or of arsenobenzol and mercury is desirable.

(2) In cases which are seen at a later period of syphilitic infection more prolonged treatment is required, and the period of observation must be longer.

(3) Patients undergoing anti-syphilitic treatment should be subjected to careful clinical examination at periodic intervals, with a view to detecting at once any symptom or sign suggesting the onset of neuro-syphilis.

(4) As soon as the slightest prodromal sign of involvement of the nervous system is detected, the cerebrospinal fluid should be examined.

(5) If the Wassermann test of the blood does not react to anti-syphilitic treatment administered over a period of six months, it is advisable to examine the cerebro-spinal fluid.

(6) In every case of syphilis it is of value to examine the cerebro-spinal fluid at the end of the first year of treatment ; even if negative results are obtained, it should be examined subsequently at a period three months after cessation from treatment before the patient is considered cured.

(7) If a pathological cerebro-spinal fluid is obtained $25 \mathrm{I}$ 


\section{BRITISH JOURNAL OF VENEREAL DISEASES}

(W.R. +++ ), it is advisable to administer tryparsamide and mercury or bismuth. The only exception to this is perhaps the case of established general paralysis of the insane.

(8) Tryparsamide, if given in sufficient dosage and over sufficiently long periods, exercises a very favourable influence on all early cases of neuro-syphilis and improves both the clinical and the serological picture.

(9) On account of its tonic action and the absence of any serious manifestations of intolerance, this drug can be given over long periods ; it should be administered in every case for a considerable period after the disappearance of both clinical and serological signs of disease.

(Io) In established general paralysis of the insane and in those cases of neuro-syphilis which prove intractable to tryparsamide and bismuth, malarial treatment is indicated; it is important to administer further treatment with tryparsamide and bismuth subsequent to the malarial therapy in order to obtain the best results.

(II) We are satisfied that the prognosis and outlook for many cases of neuro-syphilis has undergone a complete and very favourable change. Since these two methods of treatment, either alone or in combination, have been practised, complete remission of symptoms is frequently obtained, which, we have reason to hope, may be lasting in a considerable proportion of cases.

(I2) Although our results have been favourable in many cases which have been observed for varying periods since I924, it is unwise as yet and impossible to make any definite claims for permanency of the results and for cure in patients treated by any of these methods.

\section{LITERATURE}

Astruc, Jean : Book IV., Part II., Chapter XI., p. I25, I736.

BAYLE : Recherches sur les Malades Mentales, Paris, 1822.

BECHT and GunNER : Amer. Journ. of Psychology, I92I, LVI., p. 23 I. Becht and Matill : Amer. Journ. of Psychology, I920, III., p. I26. BENARIO : Münch. Med. Wochenschr, No. I, I9II.

Browning and MackenzIE : Journ. of Mental Science, July, Igog. Browning and MackenzIE: "Diag. and Treat. of Syphilis," 2nd Edit., p. 499, London, I924.

Corning, J. L.: New York Med. Journ., I885, XLII., p. 483.

Esquirol: "Thése 'Emotions considered as causes, symptoms and means of treatment in Insanity," " Paris, I805.

EsQUIROL : "Dictionary of Mental Sciences," I8I4. 


\section{SYPHILIS OF THE ·NERVOUS SYSTEM}

Fordyce : Journ. Cutaneous Diseases, October Ist, I9I6.

GenNerICH: "Syphilis of the Central Nervous System," Berlin, I92I.

HASLAM : 'Observations on Insanity,” Ist Edit., London, V., I798.

JEANS: Amer. Journ. Diseases of Children, I9I9, XVIII., p. I73.

Kaliski and Strauss: Arch. Neurol. and Psychiat., I922, VII., pp. 98 and Io2.

KIngery : Journ. Amer. Med. Assoc., January, I93I, LXXVI., pp. I2-I3.

Levaditi and Marie: Compt. Rend. Acad. Scien., June 2nd, I9I4. LeVaditi and MARIE : Annales Pasteur Inst., XXXIII., I9I9, p. 74r. LEVADITI and MARIE : Annales Pasteur Inst., I923, XXXVII., p. I89. LORENZ et alia ; Wes. Med. Journ., I922, XX., p. 336.

LoREnZ et alia; Jour. Amer. Med. Assoc., I923, LXXX., p. I497.

MARINESCO : Rev. Neurol., December, I9I9, XXII., p. 901.

Mills, C. H. : Brit. Med. Journ., September, I928.

Motт, F. : Brit. Med. Journ., July 7 th, I923, p. 24

NogUCHI and MoORE : Journ. Exper. Med., I9I3, XVII., p. 232.

PeArce, Louise: Journ. Exper. Med., I92I, XXXIV., 6, Suppl. I.

PeArce, Louise: Journ. Exper. Med., November, I9I9, XXX., p. 4I7.

Pearce and Brown : Journ. Exper. Med., I92I, XXXIII., p. I93.

Ravaut: Bull. et Mem. Soc. Med. Hôp. Paris, I903, XX., p. Io26. Ravaut: Ann. Dermat. et Syph., I907, VIII., p. 8I.

Ravaut, Widal and Siccard : Rev. Neurology, I903, XI., p. 289.

Robertson, G. M. : Ed. Med. Journ., I9I3, pp. 293 and 428.

SACHS: Journ. Amer. Med. Assoc., September Ist, I9I7, LXIX., p. 68I.

SEnNERT : “Practice of Medicine," Wittenberg, I835, quoted by Deutch. Med. Woch., I927, p. I9I3.

Swift and Ellis: Journ. Amer. Med. Assoc., December 22nd, I9I7, LXXXí, p. 2092.

SwIFT and ElLIS: Forehheimer's "Therapeusis of Internal Diseases," I9I4, p. 40I. 